\title{
Dielectric and impedance spectroscopy of aluminium oxide substituted fused silica samples
}

\author{
Manisha Sahu ${ }^{1} \cdot$ Sugato Hajra ${ }^{1} \cdot$ Kalyani Mohanta $^{2} \cdot$ Varsa Purohit $^{3} \cdot$ R. N. P. Choudhary ${ }^{3}$
}

(C) Springer Nature Switzerland AG 2019

\begin{abstract}
This paper shows a comparative study of sintered and thermally quenched $\mathrm{Al}_{2} \mathrm{O}_{3}$ substituted fused silica ceramics processed by colloidal suspension route. The structural analysis is performed using X-ray diffraction measurements. The natural surface micrographs present close packing of non-uniform shape of grains. The high permittivity and low loss are illustrated from frequency dependent permittivity. The impedance spectroscopy shows non-Debye type relaxation mechanism. The Nyquist plot shows the presence of only grain effect. The overlapping large Polaron tunnelling model is attributed from the conduction studies of both sintered and quenched samples.
\end{abstract}

Keywords XRD $\cdot$ Silica $\cdot$ Impedance $\cdot$ Conductivity

\section{Introduction}

Extensive research work is being carried out in the field of advance materials due to their potential in development and commercialization of electronic components [1]. The lead-based ceramics are often preferred by various electronics industry due to the superior properties. The strict regulations made by various world agencies have banned the lead-based products looking into its toxicity declining public health and environment [2]. Fused silica acts as an antenna window in spacecraft having low dielectric parameters, low thermal expansion and high melting point [3]. Alumina has various crystalline phases with high strength and stiffness. $\mathrm{Al}_{2} \mathrm{O}_{3}$ ceramics have low permittivity $\left(\varepsilon_{\mathrm{r}} \sim 10\right)$ and quality factor $\left.\sim 50,000 \mathrm{GHz}\right)$. Sriharan et al. [4] fabricated and characterize the $\mathrm{Al}_{2} \mathrm{O}_{3}$ doped $\mathrm{TiO}_{2}$ composites derived from soft chemical route. Luo et al. [5] reported the electrical properties of $\mathrm{Al}_{2} \mathrm{O}_{3}$ doped $\mathrm{ZnO}$. The structural and electrical properties of pure fused silica were reported by same authors [6]. The effect of alumina on mechanical properties of fused silica ceramics is reported by Wan et al. [7]. The colloidal processing helps to generate uniform microstructural. It possibly combines various consolidate mechanisms to fabricate complex materials [8]. Some of the dopants like $\mathrm{Al}_{2} \mathrm{O}_{3}$ plays a vital role in reducing the sintering temperature and enhance the mechanical strength. The certain factors such as content of impurity, particle size, synthesis step effects the doping amount of $\mathrm{Al}_{2} \mathrm{O}_{3}$.

Detailed studies of the reported literature show that no clear results regarding the electrical properties of $\mathrm{Al}_{2} \mathrm{O}_{3}$ substituted fused silica samples are reported so far. Therefore, in this paper, the motivation lies in (a) finding a correlation between the structure and physical properties, and (b) understanding of the electrical parameters using complex impedance spectroscopy as well as conduction mechanism in sintered and quenched samples of $\mathrm{Al}_{2} \mathrm{O}_{3}$ substituted fused silica.

$\triangle$ Manisha Sahu, manishafl@outlook.com | 'Department of Electronics and Instrumentation, Siksha O Anusandhan University, Bhubaneswar 751030, India. ${ }^{2}$ Department of Ceramic Engineering, Indian Institute of Technology-BHU, Varanasi, Uttar Pradesh 221005 , India. ${ }^{3}$ Multifunctional and Advance Materials Laboratory, Siksha O Anusandhan University, Bhubaneswar 751030, India. 


\section{Sample processing and experimental techniques}

\subsection{Ceramic suspension processing}

Fused silica powder (M/S Chettinad Fused quartz Pvt. Ltd, India) and alumina powder (CT3000-SG, Alcoa-USA) was used to fabricate the samples by colloidal processing route. Egg white (fresh eggs extract) and sucrose (Loba Chemie, India) acted as a binder for preparation of suspension. In order to achieve homogenization egg white was stirred employing magnetic stirrer for $2 \mathrm{~h}$. Further various ratios distilled water (premix) was mixed along with egg white and/or sucrose. This premix helps to synthesize the $\mathrm{Al}_{2} \mathrm{O}_{3}$ doped fused silica suspensions. 55-70 vol\% loading added suspensions were further subjected to roll milling the premix with $\mathrm{Al}_{2} \mathrm{O}_{3}$ and fused silica powders in polypropylene bottles employing $3 \mathrm{~mm}$ zirconia grinding media for $24 \mathrm{~h}$. The bubble formation (i.e. arises due to egg white) during the suspension preparation was controlled by 1 -octanol $(5 \mathrm{~mL} / 100 \mathrm{~mL}$ of egg white). The zirconia media are filtered out from suspensions after $24 \mathrm{~h}$ of milling, and different measurements were performed. The obtained suspensions were cast into petroleum jelly-coated rectangular aluminium molds and kept in hot oven at $60^{\circ} \mathrm{C}$ for $24 \mathrm{~h}$ for drying purpose. The green parts were separated from mold after it reached room temperature, and further heated for $24 \mathrm{~h}$ in an oven. All samples were kept at $900{ }^{\circ} \mathrm{C}$ for $2 \mathrm{~h}$ to ensure complete burnout of the organics and achieve sufficient handling strength. Then the sintering is done at $1100^{\circ} \mathrm{C}$ in a high temperature furnace with soaking period for $2 \mathrm{~h}$. The as-sintered $\mathrm{Al}_{2} \mathrm{O}_{3}$ substituted fused silica samples were subjected to thermal cycling for 5 times. A single thermal cycle comprises of heating to $900{ }^{\circ} \mathrm{C}$, a $30 \mathrm{~min}$ dwell at $900^{\circ} \mathrm{C}$ followed by quenching in chilled water $\left(5^{\circ} \mathrm{C}\right)$.

\subsection{Experimental techniques}

The phase formation of sintered and quenched samples was evolved using Rigaku Miniflexll X-ray diffractometer at a scanning rate of $2 \%$ min over Braggs angle $\left(10 \leq 2 \theta \leq 70\right.$, radiation $=\left(u k_{a}\right)$. The surface micrographs were obtained employing the FESEM (M/S FEI Nova NanoSEM 400). One of the pellets each from sintered and quenched samples were polished parallel both sides and silver-painted forming metal-insulator-metal arrangement before electrical measurements. The computer-interfaced LCR meter (UK made N4L PSM) detects the electrical properties of the samples (sintered and quenched) as a function of frequency $\left(10^{3}-10^{6} \mathrm{~Hz}\right)$ and temperature $\left(25-500^{\circ} \mathrm{C}\right)$. Figure $1 \mathrm{a}$ shows systematic representation of the synthesis and characterization carried out.

\section{Results and discussions}

\subsection{Structural and morphological analysis}

Figure $1 \mathrm{~b}$ shows the structural analysis of the sintered and quenched samples. It is well known that beyond the $1100^{\circ} \mathrm{C}$ the crystallization starts forming dispersed cristobalite crystals during fused silica processing. Hence at $1100{ }^{\circ} \mathrm{C}$, the formation of the prepared samples is confirmed. The surface morphology and densification are illustrated in Fig. 2 (a) sintered and (b) quenched. It suggests that the pattern of grains is irregular and non-uniform having varying sizes. It depicts maximum grains are packed closely throughout the surface without cracks. The density of the sintered sample is $1.7 \mathrm{gm} / \mathrm{cc}$ while a slight increase in density is seen for the quenched sample that is $1.9 \mathrm{gm} /$ cc. Figure 3 shows the EDX spectra of (a) sintered and (b) quenched samples. It suggests that all the elements are presented similar to base composition without any trace of impurity.

\subsection{Analysis of dielectric parameters}

The dipoles of dielectrics rearrange in a particular direction as subjected to an electric field, and exhibit alignment of polar charges. The dielectric material tries to reorient and neutralize charges on the electrodes can express in terms of a transfer function coined as dielectric permittivity. The dielectric permittivity of most dielectric materials is frequency dependent. Figure $4(a, b)$ presents the relative dielectric constant $\left(\varepsilon_{r}\right)$ and loss tangent $(\tan \delta$ ) at different frequencies and temperatures for both as-sintered and quenched $\mathrm{Al}_{2} \mathrm{O}_{3}$ substituted fused silica samples. The $\varepsilon_{r}$ and $\tan \delta$ value falls on enhancement of frequency, which is a common trend of oxide materials. The different polarizations (interfacial, dipole, atomic, ionic, and electronic) have been dominant in low-frequency region [9]. The polarization fades away with enhancement of frequency slowly; as a result, dielectric constant decreases for both samples. The loss factor is the estimate of how dissipative material is when subjected to an external electric field. Figure $4 a$, $b$ inset shows the loss has a similar trend like dielectric constant. At lower frequency the spectra show dispersive nature and the trend coincides at higher frequency depend mainly on the contribution of space charge polarization. It is well known that the $\tan \delta$ has two parts: (1) relaxation part (Debye or non-Debye) and 
(a)
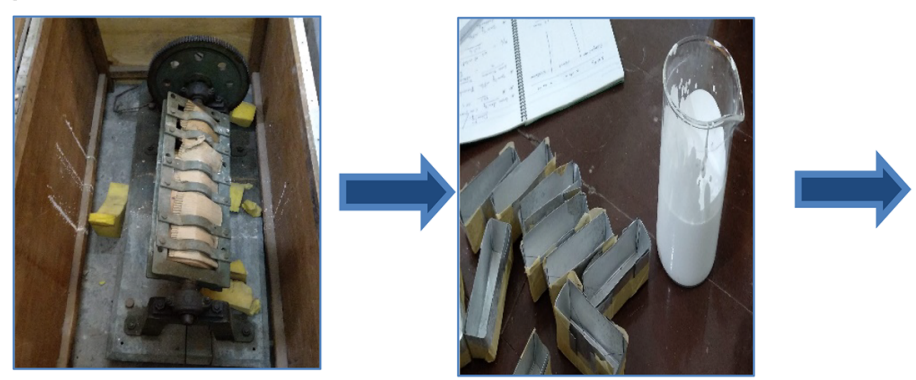

\section{Sintered}

\section{Quenched}
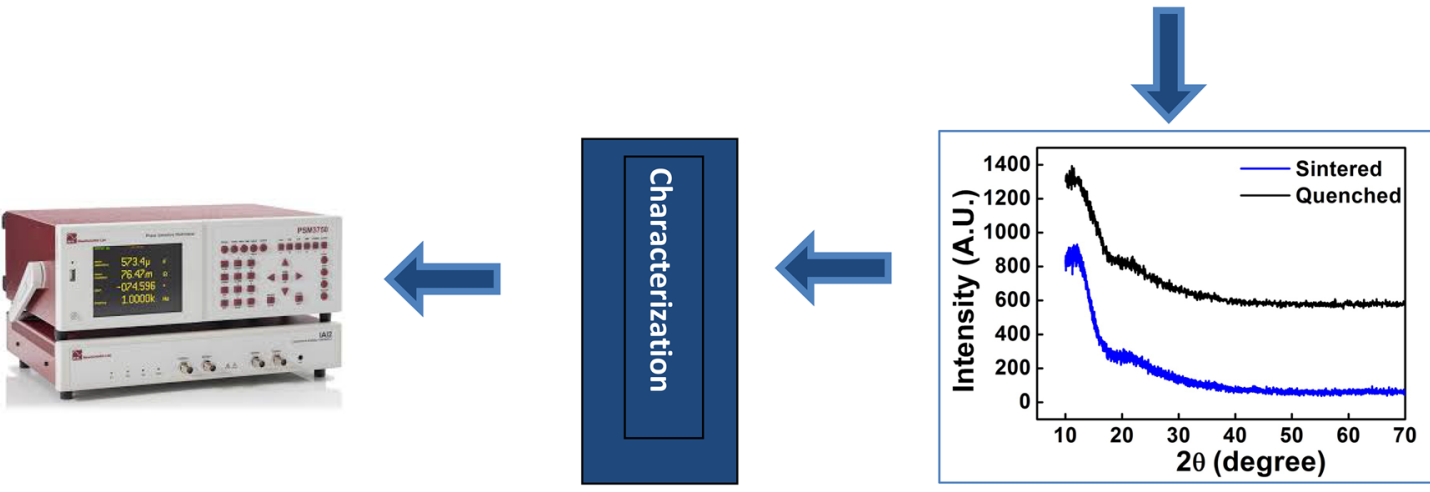

(b)

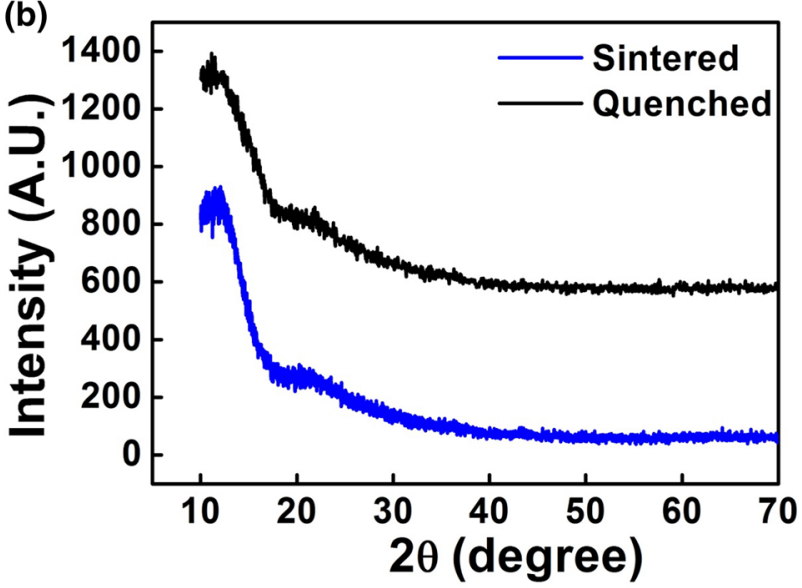

Fig. 1 a The representation of synthesis and further characterization process of samples. $\mathbf{b}$ XRD pattern of sintered and quenched $\mathrm{Al}_{2} \mathrm{O}_{3}$ substituted fused silica samples at room temperature

(2) dc conductivity part. The relaxation peaks are absent in both sintered and quenched samples in the experimental temperature range. The loss factor value increases as the frequency rise due to charge carriers and unknown defects [10].

\subsection{Complex impedance analysis and Nyquist plot}

The complex impedance spectroscopy (CIS) tool was designed by Bauerle [11] to shed light upon the polarization process in the materials. CIS helps to get information about the electrical characterization of polycrystalline materials [12]. It suggests about homogeneous (bulk) and inhomogeneous distribution of grains, grain-boundary, electrolyte-electrode interface process, porosity in the materials.

Figure $5 a, b$ presents the change of $Z^{\prime}$ with frequency at a few temperatures. The low-frequency dispersion is depicted for all curves, form a plateau at higher frequency. The relaxation process is delayed due to space charges causing the low-frequency dispersion. It is noticed that the $Z^{\prime}$ value of all the temperatures merged at high-frequency. The presence of combined PTCR (positive temperature coefficient of resistance)/NTCR (negative temperature 

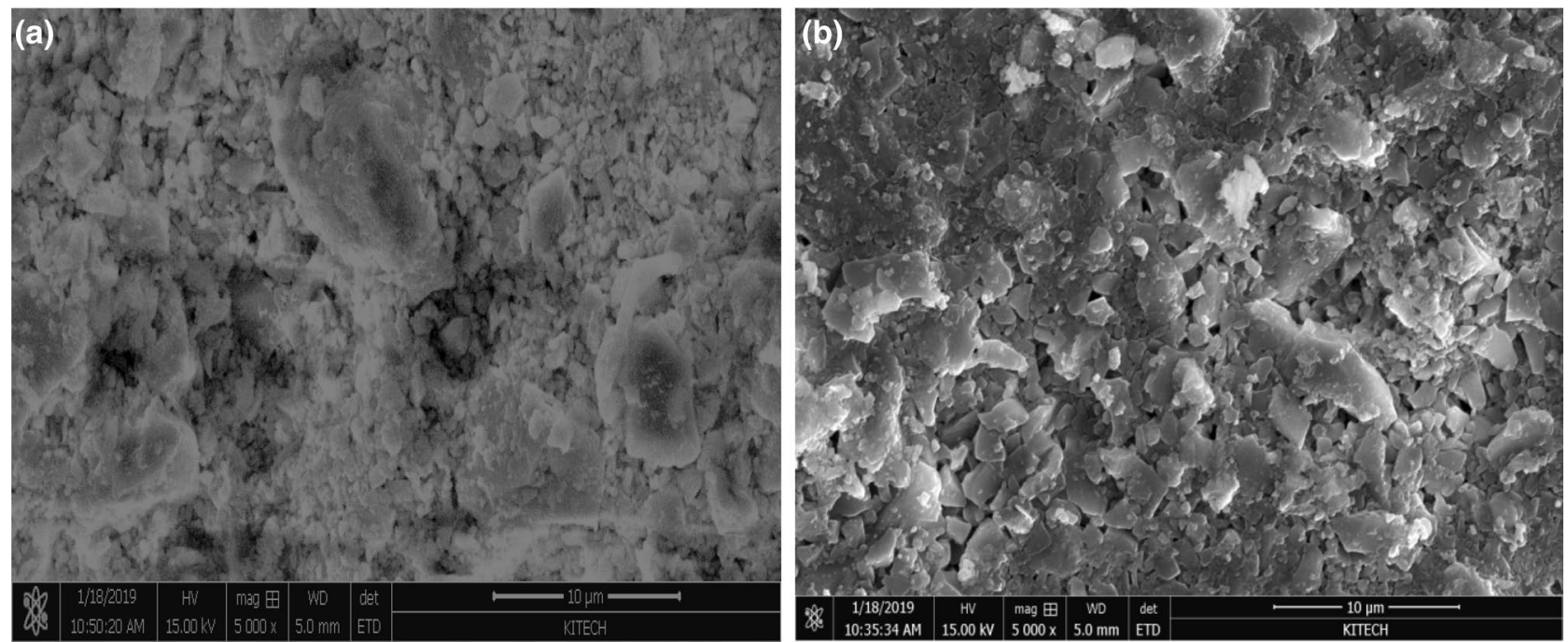

Fig. 2 Surface micrographs of a sintered, $\mathbf{b}$ quenched $\mathrm{Al}_{2} \mathrm{O}_{3}$ substituted fused silica

Fig. 3 EDX spectra showing the chemical composition of a sintered and $\mathbf{b}$ quenched $\mathrm{Al}_{2} \mathrm{O}_{3}$ substituted fused silica samples
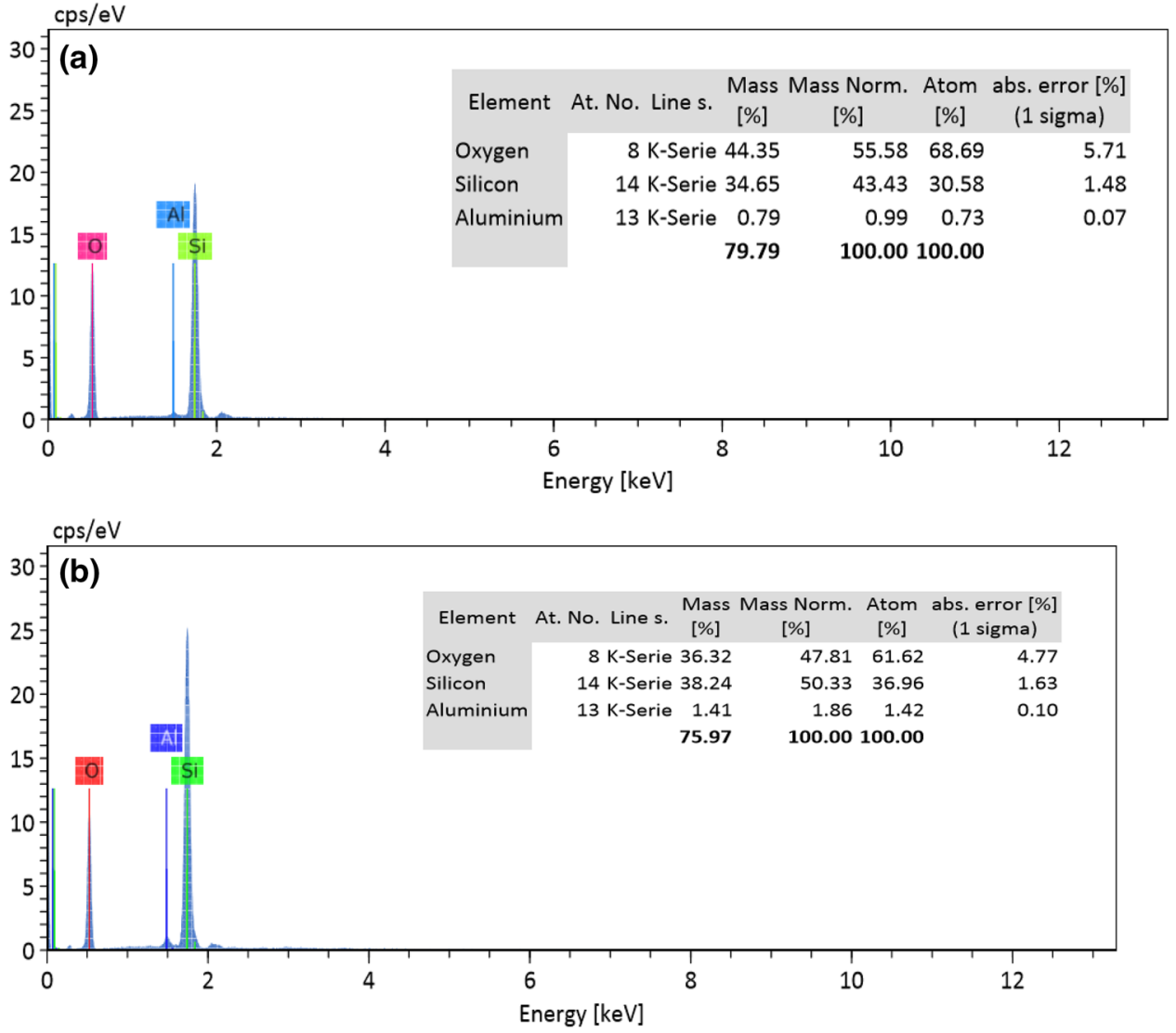

coefficient of resistance) behavior is suggested for both sintered and quenched samples as with temperature rise the value of $Z^{\prime}$ increases as well as decreases [13].

Figure $5 a, b$ inset presents the change of $Z$ " with frequency at few temperatures for both sintered and quenched samples. At a characteristic frequency $\left(\omega_{\max }=2 \pi f_{\max }\right)$ peak appears, that is independent of sample geometry, temperature-dependent and correspond to strength of the electrical relaxation in the materials. The relaxation process occurs due to immobile charges at

\section{SN Applied Sciences}


Fig. 4 Frequency dependent dielectric constant and (inset) loss factor of $\mathbf{a}$ sintered and $\mathbf{b}$ quenched of $\mathrm{Al}_{2} \mathrm{O}_{3}$ substituted fused silica samples

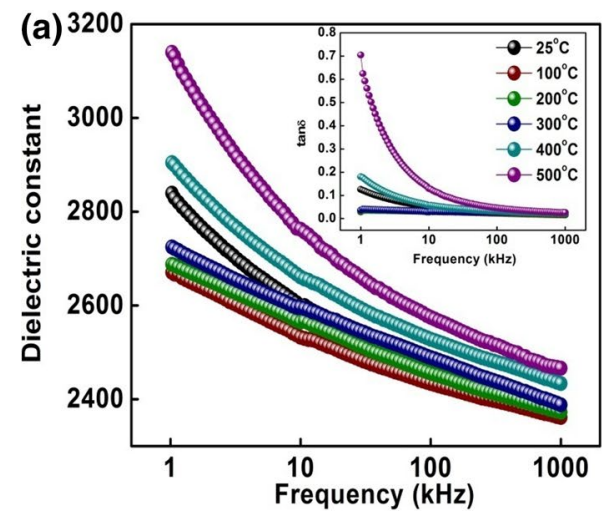

(a)
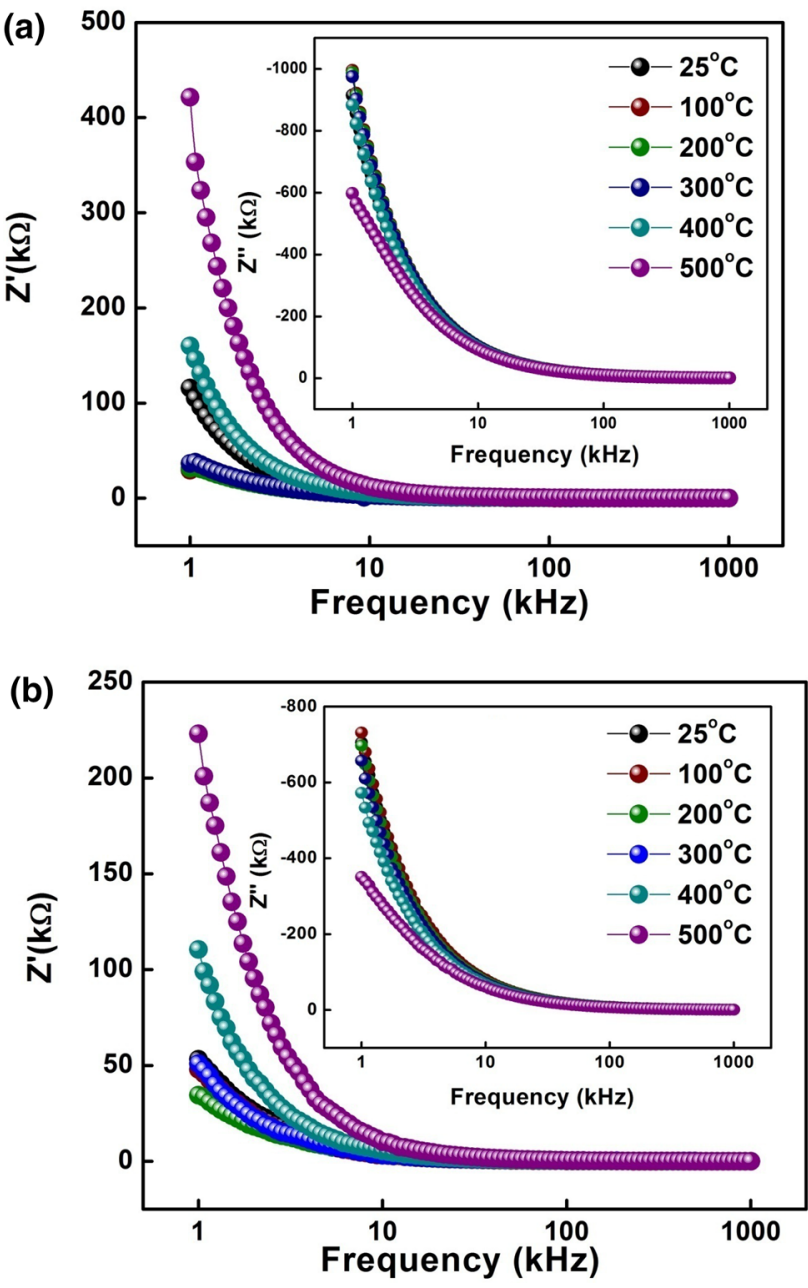

Fig. 5 Frequency dependent real and imaginary part of impedance a sintered and $\mathbf{b}$ quenched $\mathrm{Al}_{2} \mathrm{O}_{3}$ substituted fused silica samples

lower temperatures and vacancies at higher temperatures [14]. The asymmetric relaxation peaks with a broad distribution of relaxation times, suggesting Non-Debye type behavior in both sintered and quenched samples [15].
Figure $6 a$, $b$ presents the variation of Nyquist plot of both sintered and quenched samples at selected temperatures. It is well known that; the Debye or non-Debye type relaxation mechanisms can be resolved from the shape of the semi-circular arc depicted in the Nyquist plot. In general, a full or partial semicircle depends on the relaxation strength and experimental range of frequency. These experimental data are usually fitted with an equivalent circuit comprising of resistance (R), capacitance $(C)$ and constant phase elements $(Q)$ connected in a parallel configuration to analyze the transport properties of the material. The circuit model suggests the kind of impedances and their arrangement (series/parallel) in the sample and compares the temperature dependence of the resistance and capacitance values to that of the simulated one. For both sintered and quenched samples, depressed semicircle (i.e., non-Debye-type response) suggests a new circuit model is needed to fit it. The occurrence of asymmetric semi-circle shows non-Debye type of relaxation in both the sintered and quenched samples $[16,17]$. The circuit model used for fitting the impedance data of sintered and quenched sample is RQC. This suggests only grain effect is present at all temperatures for both the sintered and quenched samples.

\subsection{Conductivity analysis}

The ac conductivity in bulk materials occurs due to (a) long-range ac conductivity and (b) localized transport oxygen vacancies. To shed light on electrical transport properties, the ac conductivity needed to be explored. The frequency dependence of ac conductivity is explained using Jonscher's power law [18], $\sigma_{\mathrm{ac}}(\omega)=\sigma$ (o) $+\sigma_{1}(\omega)=\sigma_{d c}+A \omega^{n} ; 0<n<1$, where symbols have similar meaning. The $\sigma_{a c}$ rise on increasing frequency in the high-temperature region for sintered and quenched samples due to space charge polarization [19]. The $n$ value lies between zero and one. The universal power 
Fig. 6 Nyquist plot of a sintered and $\mathbf{b}$ quenched samples at selected temperatures

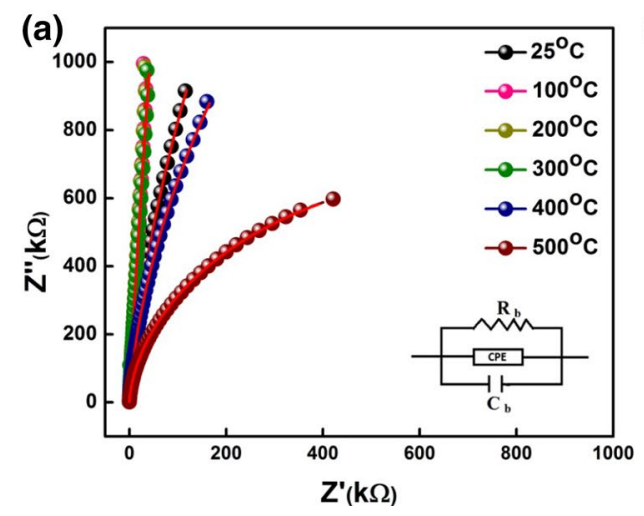

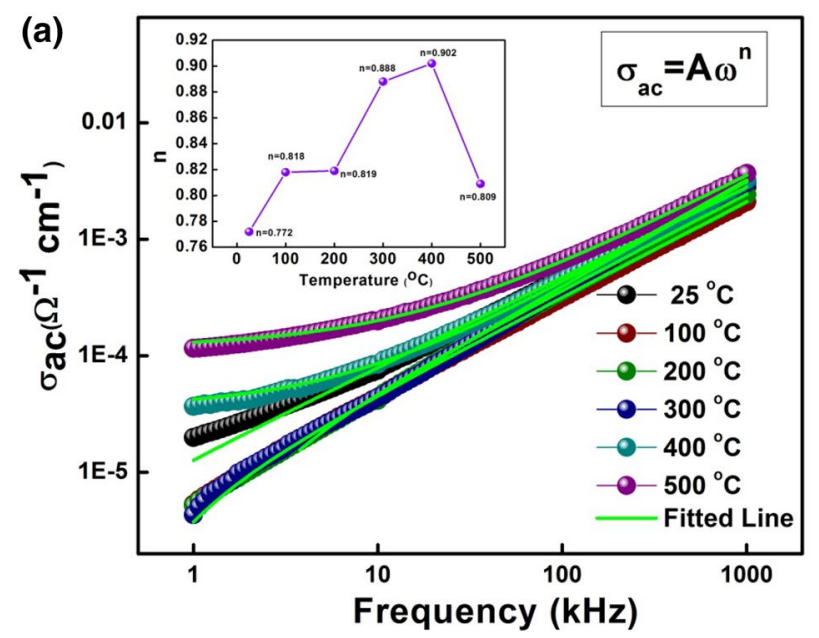

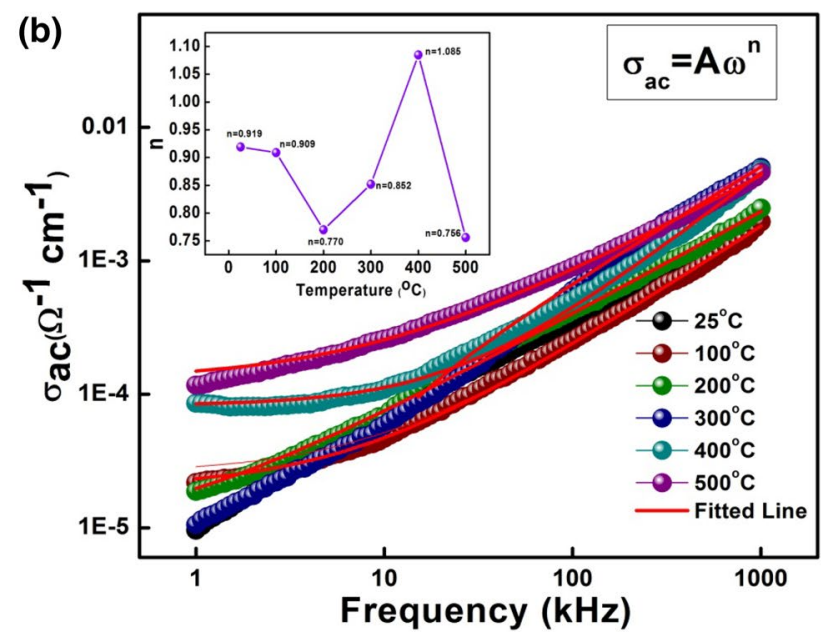

Fig. 7 Frequency dependent $A C$ conductivity a sintered; b quenched $\mathrm{Al}_{2} \mathrm{O}_{3}$ substituted fused silica samples and (inset) illustrates the change of $\mathrm{n}$ value with temperature

law is obeyed by both plots depicted from the best fit of above equation to the experimental data (Fig. 7a, b), where solid line corresponds to fitted curve and symbols are experimental data. The $\mathrm{n}$ value less than 1 showing hopping motion having translational motion with a sudden hopping whereas $\mathrm{n}>1$ means that the motion involves localized hopping without the species leaving the neighborhood [20]. The equation $\sigma_{A C}=A \omega^{\text {n}}$; where the constant dependent temperature is represented by $A, \omega$ shows the angular frequency and the power-law exponent is given by $n$, where $n$ is between $0<n<1$ [21]. Here from (inset) it is depicted that the $n$ value first decreases and thereby increases with rise in temperature depicting an overlapping large Polaron tunnel mechanism (OLPT) [22].

\section{Conclusion}

The lead-free $\mathrm{Al}_{2} \mathrm{O}_{3}$ doped fused silica is fabricated using colloidal processing technique. The XRD pattern illustrated that the fabricated material has formed. The SEM micrographs show a densely packed surface morphology for sintered and quenched samples. The frequency-dependent AC conductivity plot obeys Jonscher's universal power law for both the sintered and quenched samples. Comprehensive analysis of impedance characteristics illustrated the non-Debye type of relaxation phenomena, the subsistence of NTCR/PTCR type behavior in the sintered and quenched samples. The above results suggest that the prepared leadfree samples are low loss material suitable for advance filter applications.

Acknowledgements The authors like to thank KITECH, South Korea for helping in the SEM experiment in their central facility.

\section{Compliance with ethical standards}

Conflict of interest The authors declare that they have no conflict of interest. 


\section{References}

1. Spaldin NA, Cheong SW, Ramesh R (2010) Multiferroics: past, present, and future. Phys Today 63:38

2. Kumar A, Prasad VVB, Raju KCJ, James AR (2014) Ultra high strain properties of lanthanum substituted PZT electro-ceramics prepared via mechanical activation. J Alloys Compd 599:53-59

3. Wen G, Wua GL, Lei TQ, Zhou Y, Guo ZX (2000) Co-enhanced $\mathrm{SiO}_{2}$-BN ceramics for high-temperature dielectric applications. J Eur Ceram Soc 20:1923-1928

4. Sriharan N, Muthukumarasamy N, Senthil TS (2019) Preparation and characterization of $\mathrm{Al}_{2} \mathrm{O}_{3}$ doped $\mathrm{TiO}_{2}$ nanocomposites prepared from simple sol-gel method. Z Phys Chem 230:1745-1758

5. Luo Y, He K, Yu RH, Qi JP, Yuan HM, Xie J, Xu D (2019) Effect of $\mathrm{Al}_{2} \mathrm{O}_{3}$ doping on electric and dielectric properties of $\mathrm{ZnO}$ linear resistor. Mater Res Innov 18:S4-639-S4-641

6. Hajra S, Mohanta K, Sahu M, Purohit V, Choudhary RNP (2019) Studies of structural, dielectric and impedance spectroscopy of fused silica ceramics fabricated through colloidal processing. Appl Phys A 125:369

7. Wan W, Yang J, Feng Y, Bu W, Qiu T (2016) Effect of trace alumina on mechanical, dielectric, and ablation properties of fused silica ceramics. J Alloy Compd 675:64-72

8. Moreno R (2010) Colloidal processing of ceramics and composites. Adv Appl Ceram 111:246-253

9. Parida K, Dehury SK, Choudhary RNP (2017) Electrical, optical and magneto-electric characteristics of $\mathrm{BiBaFeCeO}_{6}$ electronic system. Mater Sci Eng B 225:173-181

10. Afsar MF, Jamil A, Rafiq MA (2017) Ferroelectric, dielectric and electrical behavior of two-dimensional lead sulphide nanosheets. Adv Nat Sci Nanosci Nanotechnol 8:045010

11. Bauerle J (1969) Study of solid electrolyte polarization by a complex admittance method. J Phys Chem Solids 30:2657

12. Wang T, Hu J, Yang H, Jin L, Wei X, Li C, Yan F, Lin Y (2017) Dielectric relaxation and Maxwell-Wagner interface polarization in $\mathrm{Nb}_{2} \mathrm{O}_{5}$ doped $0.65 \mathrm{BiFeO}_{3}-0.35 \mathrm{BaTiO}_{3}$ ceramics. J Appl Phys 121:084103

13. Chandrasekhar M, Khatua DK, Pattanayak R, Kumar P (2017) Dielectric relaxation and conduction mechanism studies of BNT-BT-BKT ceramics. J Phys Chem Solids 111:160-166
14. Sharma V, Kaur R, Singh M, Selvamani R, Gupta SM, Tiwari VS, Karnal AK, Singh A (2018) Conductivity relaxation and oxygen vacancies-related electron hopping mechanism in $\mathrm{Pb}_{1-x} \mathrm{La}_{x} / 2 \mathrm{Sm}_{x / 2} \mathrm{Ti}_{1-x} \mathrm{Fe}_{x} \mathrm{O}_{3}$ solid solutions. J Asian Ceram Soc 6:222-231

15. Nath S, Barik SK, Choudhary RNP, Barik SK (2017) Structural, dielectric and impedance characteristics of $\left(\mathrm{Sm}_{0.5} \mathrm{Li}_{0.5}\right)\left(\mathrm{Fe}_{0.5} \mathrm{~V}_{0.5}\right) \mathrm{O}_{3}$ multiferroics. Phys Lett A 381:2174-2180

16. Sahu M, Pradhan SK, Hajra S, Panigrahi BK, Choudhary RNP (2019) Studies of structural, electrical, and excitation performance of electronic material: europium substituted 0.9 $\left(\mathrm{Bi}_{0.5} \mathrm{Na}_{0.5} \mathrm{TiO}_{3}\right)-0.1\left(\mathrm{PbZr}_{0.48} \mathrm{Ti}_{0.52} \mathrm{O}_{3}\right)$. Appl Phys A 125:183

17. Hajra S, Tripathy A, Panigrahi BK, Choudhary RNP (2019) Development and excitation performance of lead free electronic material: Eu and Fe doped $\mathrm{Bi}_{0.5} \mathrm{Na}_{0.5} \mathrm{TiO}_{3}$ for filter application. Mater Res Express 6:076304

18. Nath S, Barik SK, Hajra S, Choudhary RNP (2018) Studies of structural, impedance spectroscopy and magnetoelectric properties of $(\mathrm{SmLi})_{1 / 2}\left(\mathrm{Fe}_{2 / 3} \mathrm{Mo}_{1 / 3}\right) \mathrm{O}_{3}$ electroceramics. J Mater Sci Mater Electron 29:12251-12257

19. Badapanda T, Harichandan RK, Nayak SS, Mishra A, Anwar S (2014) Frequency and temperature dependence behaviour of impedance, modulus and conductivity of $\mathrm{BaBi}_{4} \mathrm{Ti}_{4} \mathrm{O}_{15}$ aurivillius ceramic. Process Appl Ceram 8:145-153

20. Parida BN, Das PR, Padhee R, Choudhary RNP (2013) Structural, dielectric and electrical properties of $\mathrm{Li}_{2} \mathrm{~Pb}_{2} \mathrm{La}_{2} \mathrm{~W}_{2} \mathrm{Ti}_{4} \mathrm{Nb}_{4} \mathrm{O}_{30}$ ceramic. Bull Mater Sci 36:883-892

21. Das R, Choudhary RNP (2019) Structure, dielectric and electrical properties of relaxor lead-free double perovskite: $\mathrm{Nd}_{2} \mathrm{NiMnO}_{6}$. Process Appl Ceram 13:1-11

22. Mizouri F, Abdelmoula N, Mezzane D, Khemakhem H (2018) Impedance spectroscopy and conduction mechanism of multiferroic $\mathrm{Bi}_{0.8}\left(\mathrm{Ba}_{0.9} \mathrm{Ca}_{0.1}\right)_{0.8} \mathrm{Fe}_{0.8}\left(\mathrm{Ti}_{0.9} \mathrm{Sn}_{0.1}\right)_{0.8} \mathrm{O}_{3}$. J Alloys Compd 763:570-580

Publisher's Note Springer Nature remains neutral with regard to jurisdictional claims in published maps and institutional affiliations. 